\title{
Designing ultrafine lamellar eutectic structure in bimodal titanium alloys by semi-solid sintering
}

\author{
L.M. Kang a , C. Yang a, *, F. Wang ${ }^{\text {a }}$, X.X. Li a , D.Z. Zhu ${ }^{\text {a }, ~ W . W . ~ Z h a n g ~ a ~, ~ W . P . ~ C h e n ~}{ }^{\text {a }}$, \\ Y. Huan ${ }^{\text {b** }}$ \\ ${ }^{a}$ National Engineering Research Center of Near-net-shape Forming for Metallic Materials, South China University of Technology, Guangzhou 510640, China \\ ${ }^{\mathrm{b}}$ State Key Laboratory of Nonlinear Mechanics, Institute of Mechanics, Chinese Academy of Sciences, Beijing 100190, China
}

\section{A R T I C L E I N F O}

Article history:

Received 19 November 2016

Received in revised form

18 January 2017

Accepted 22 January 2017

Available online 25 January 2017

\section{Keywords:}

Bimodal titanium alloys

Eutectic

Semi-solid

Liquid phase sintering

Spark plasma sintering

\begin{abstract}
A B S T R A C T
We report on a novel approach to design typical ultrafine lamellar eutectic structure in bimodal alloys fabricated by semi-solid sintering (SSS) of a eutectic mixture. In our work, ultrafine lamellar eutectic structure was implemented by controlling the phase composition of eutectic reaction, and consequently by regulating the structure of eutectic reaction-induced liquid phase through varying component number. Microstructure analysis indicate that although all SSSed alloys have the same three phase constitutions of bcc $\beta$-Ti, bcc Ti(Fe, $\mathrm{Co})$, and fcc $\mathrm{Ti}_{2}(\mathrm{Co}, \mathrm{Fe})$, the morphology and distribution of the eutectic structure transforms from limited length and minor quantity, to partial fine alternating bcc $\beta$-Ti and bcc $\mathrm{Ti}(\mathrm{Fe}, \mathrm{Co})$ lamellae, and further to typical complete ultrafine alternating continuous lamellae in the SSSed ternary Ti-Fe-Co, quaternary Ti-Fe-Co-Nb, and quinary Ti-Fe-Co-Nb-Al alloys. Interestingly, the SSSed Ti-Fe-Co-Nb-Al alloy presents a novel bimodal microstructure of coarse fcc $\mathrm{Ti}_{2}(\mathrm{Co}, \mathrm{Fe})$ surrounded by an ultrafine lamellar eutectic matrix containing ultrafine bcc $\beta$-Ti and bcc Ti(Fe, Co) lamellae. This bimodal microstructure exhibits ultra-high yield strength of $2050 \mathrm{MPa}$ with plasticity in compression of $19.7 \%$, which exceed published values of equivalent materials. Our results provide a novel pathway for fabricating new-structure metallic alloys for high-performance structural applications.
\end{abstract}

(c) 2017 Elsevier B.V. All rights reserved.

\section{Introduction}

The pursuit of higher strength accompanied by larger ductility is a topic of perennial interest among metallurgists. Scientific workers have developed various strategies to achieve so-called bimodal or multimodal microstructures, which exhibit high strength without sacrificing ductility [1-13]. Among these strategies, the most extraordinary is formation of a titanium alloy with bimodal microstructure containing an fcc nanostructured matrix and micron-sized bcc $\beta$-Ti dendrites by rapid solidification based on semi-solid processing [1-3]. In addition recrystallization induced by plastic deformation and heat treatment $[9,10]$, consolidation of blended powders with different grain sizes [11], and recrystallization during powder consolidation [12] are effective strategies to

\footnotetext{
* Corresponding author.

** Corresponding author.

E-mail addresses: cyang@scut.edu.cn (C. Yang), huany@lnm.imech.ac.cn (Y. Huan).
}

obtain bimodal or multimodal microstructures containing finergrained matrix and coarser-grained dispersed phases. Especially, the typical metallurgical pathways used to obtain bimodal titanium alloys based on semi-solid processing are preferential nucleation and growth of micron-sized ductile bcc $\beta$-Ti dendrites from hightemperature melts followed by rapid solidification of the remaining liquid with a dense random-packed structure to form an fcc nanostructured matrix [1].

As one of the most significant types of phase transformation in metallography, eutectic reaction is frequently utilized to design various microstructures by using rapid solidification. Metallic glasses represent a successful example of designing a microstructure based on a eutectic reaction or eutectic composition. For example, the composition of bulk glass formers is typically associated with a deep eutectic point in which the liquid phase has a highly dense random-packed structure $[14,15]$. Another successful example is ultrafine lamellar eutectic-micrometric dendrite bimodal titanium alloys in ternary Ti-Fe-X (X = Co, Ta, Sn, Ga, In, Zr, $\mathrm{Nb})[2-4,6-8,16-21]$. In such cases, the lamellar eutectic structure possesses high yield strength ( $2175 \mathrm{MPa})$ but limited compressive 
plasticity (about 3.6\%) [2-4,6-8,16,19-21]. However, combinations of elements fewer than five fail to meet the requirement of a highly dense random-packed structure for a eutectic liquid, due to absence of atomic size mismatch [14,15]. Fortunately, a multicomponent $\mathrm{Ti}_{62} \mathrm{Nb}_{12.2} \mathrm{Fe}_{13.6} \mathrm{Co}_{6.4} \mathrm{Al}_{5.8}$ alloy succeeds in forming a highly dense random-packed structural liquid phase by a preferential eutectic reaction between bcc $\beta$-Ti and bcc TiFe [22]. This observation led to the idea of developing a novel semi-solid sintering (SSS) method that involves sintering nano-composite powder followed by subsequent semi-solid treatment to produce bimodal microstructure composed of bcc $\beta$-Ti and bcc TiFe nanostructured matrix together with micron-sized fcc $\mathrm{Ti}_{2}(\mathrm{Co}, \mathrm{Fe})$ twins. However, lamellar eutectic structure that is typically associated with a solidified eutectic liquid has not been achieved in SSSed $\mathrm{Ti}_{62} \mathrm{Nb}_{12.2} \mathrm{Fe}_{13.6} \mathrm{Co}_{6.4} \mathrm{Al}_{5.8}$ bimodal alloy. Therefore, it becomes an interesting and important question whether a lamellar eutectic structure can be introduced into bimodal titanium alloys by controlling the structure of a eutectic liquid phase.

Based on the Ti-Fe and Ti-Co binary phase diagrams [23], there are eutectic reactions that occur at $1085{ }^{\circ} \mathrm{C}$ between bcc TiFe and bcc $\beta$-Ti and at $1020^{\circ} \mathrm{C}$ between fcc $\mathrm{Ti}_{2} \mathrm{Co}$ and bcc $\beta$-Ti, respectively. The melting point of $\beta$-Ti solid solution ranges $1570-1980{ }^{\circ} \mathrm{C}$, depending on the $\beta$-stabilizer added [24,25]. Generally, the melting point of TiFe or $\mathrm{Ti}_{2} \mathrm{Co}$ solid solution is far higher than its eutectic reaction temperature. Consequently, an idea arises: if a multi-phase alloy powder containing the above three phases is heated to the temperature intervals between the two eutectic reaction points or between some eutectic point and the melting point of some solid solution, a liquid phase induced by preferential eutectic reaction between two solid phases would form and thus the alloy powder would enter a semi-solid state. Carefully controlling the phase composition of eutectic reaction, and consequently regulating the structure of eutectic reaction-induced liquid phase would provide a pathway to tailor the microstructure of SSSed bulk alloys. As such, the target alloy composition was designed as varied components from the base alloy of ternary $\left(\mathrm{Ti}_{70.56} \mathrm{Fe}_{29.44}\right){ }_{90} \mathrm{Co}_{10}$ (at.\%, all the same hereafter), to quaternary $\left(\mathrm{Ti}_{63.5} \mathrm{Fe}_{26.5} \mathrm{Co}_{10}\right)_{87.8} \mathrm{Nb}_{12.2}$ with added $\beta$-stabilizer $\mathrm{Nb}$, and further to quinary ( $\mathrm{Ti}_{63.5} \mathrm{Fe}_{26.5-}$ $\left.\mathrm{Co}_{10}\right)_{82} \mathrm{Nb}_{12.2} \mathrm{Al}_{5.8}$ with added $\alpha$-stabilizer $\mathrm{Al}$, successively. The atomic ratio of $\mathrm{Ti} / \mathrm{Fe}$ in the ternary alloy corresponds exactly to the eutectic composition in Ti-Fe phase diagram [23], and the minor Co addition promotes the formation of bcc $\mathrm{Ti}(\mathrm{Fe}, \mathrm{Co})$ solid solution and the formation of fcc $\mathrm{Ti}_{2} \mathrm{Co}$ and further fcc $\mathrm{Ti}_{2}(\mathrm{Co}, \mathrm{Fe})$ [7] due to reciprocal infinite dissolution between $\mathrm{Fe}$ and $\mathrm{Co}[7,26]$. The $\mathrm{Nb}$ addition in the quaternary alloy stabilizes and regulates the content of bcc $\beta$-Ti in eutectic reaction. The $\mathrm{Nb}$ and $\mathrm{Al}$ addition accelerates the formation of highly dense random-packed liquid phase because of atomic size mismatch $[14,15]$. It is worth noting that the resultant eutectic liquid phase in alloy system with more components added would have a more dense random-packed structure $[2,15]$ thereby providing a pathway to achieve finer-grained microstructure and thus fabricate novel bimodal microstructures.

Motivated by this question, we report on designing typical ultrafine lamellar eutectic structure in bimodal alloys fabricated by semi-solid sintering of a eutectic mixture varying from ternary TiFeCo to quaternary TiFeCoNb further to quinary TiFeCoNbAl alloy. Interestingly, the typical lamellar eutectic matrix with alternating ultrafine bcc $\beta$ - $\mathrm{Ti}$ and $\mathrm{Ti}(\mathrm{Fe}, \mathrm{Co})$ lamellae is accompanied by a coarse equiaxed fcc $\mathrm{Ti}_{2}(\mathrm{Co}, \mathrm{Fe})$ in the resultant quinary bimodal alloys. This bimodal microstructure is obviously different from those of bimodal titanium alloys reported so far [1-11,13,22], and thus leads to a significant improvement in mechanical property, superior to those of bimodal titanium alloys reported so far $[1-11,13,22]$.

\section{Material and methods}

The experimental procedure starts by preparation of glassy powder by mechanical alloying. Respective elemental powders of high-purity titanium (>99.5 wt\%), iron (>99.8 wt\%), cobalt (>99.8 wt\%), niobium (>99.95 wt\%), aluminum (>99.7 wt\%) were mixed in accordance with the designed three compositions, and blended homogeneously for $24 \mathrm{~h}$ under high-purified argon atmosphere by a mechanical mixer (ABB ACS 100). Mechanical alloying was performed in stainless steel containers with steel balls (weight ratio of ball to powder is 5:1) at a rotation rate of $248 \mathrm{rpm}$ in high-purified argon atmosphere by a high-energy planetary ball milling system (QM-2SP20-CL, made by apparatus factory of Nanjing University). Approximately $3 \mathrm{~g}$ of the milled powders were taken out from the mill containers every $10 \mathrm{~h}$ for X-ray diffraction (XRD) examination (D/MAX-2500/PC; Rigaku Corp., Tokyo, Japan), differential scanning calorimetry analysis (DSC, Netzsch STA 409 C), and a Tecnai G2 F30 high resolution transmission electron microscopy observation (HRTEM; FEI, Eindhoven, The Netherlands), until the formation of glassy powders with maximized glassy matrix and remained $\beta$-Ti nanocrystals after dozens of hours milling. In order to prove existence of so-called semi-solid state and optimize sintering parameters during SSS, the DSC was employed to determine the semi-solid temperature interval of the as-milled glassy powders at $10^{\circ} \mathrm{C} / \mathrm{min}$ under a high-purified argon atmosphere.

The SSS in this study was implemented by a two-step method under continuous heating to the semi-solid temperature interval under an argon atmosphere in a Dr. Sintering SPS (Spark Plasma Sintering)-825 system. First, the as-milled glassy powders were protected by a piece of tantalum foil ( $28 \mu \mathrm{m}$ in thickness), inserted into a graphite mold and pre-compacted under $20 \mathrm{MPa}$, then preheated at a heating rate of $50{ }^{\circ} \mathrm{C} / \mathrm{min}$ from room temperature to $200{ }^{\circ} \mathrm{C}$ under a sintering pressure of $30 \mathrm{MPa}$, and then sintered sequentially at a heating rate of $100{ }^{\circ} \mathrm{C} / \mathrm{min}$ from $200{ }^{\circ} \mathrm{C}$ to a preselected sintering temperature $\left(50^{\circ} \mathrm{C}\right.$ below the temperature of the preferential eutectic reaction between two solid phases). Note at this step the sintered specimens have almost achieved near full density. Second, the semi-solid treatment involved decreasing the sintering pressure from $30 \mathrm{MPa}$ to $20 \mathrm{MPa}$ to prevent extrusion of liquid phase; the sintered specimens were continuously heated to some selected temperature inside semi-solid temperature intervals at $15{ }^{\circ} \mathrm{C} / \mathrm{min}$ to avoid temperature spikes and held for $5 \mathrm{~min}$, then cooled in a sintering furnace to $600{ }^{\circ} \mathrm{C}$ under $20 \mathrm{MPa}$ by switching off power supply, and finally cooled to room temperature under no pressure. During SSS, the macroscopic sintering temperature was controlled by a thermocouple. Instantaneous values of sintering parameters, such as temperature, punch displacement, and time, were recorded every $2 \mathrm{~s}$ by the machine software. Densification rate of the as-milled glassy powder was determined by derivative of punch displacement versus time. All sintered bulk specimens have a cylindrical shape with dimensions of $\Phi 15 \times 10 \mathrm{~mm}$. For comparison purposes, cylindrical rod samples with the designed three compositions were fabricated using copper mold casting from high purity raw materials. The obtained cylindrical rod samples have a diameter of $6 \mathrm{~mm}$.

The phase constitution, microstructure and/or fractography of the SSSed and cast specimens were characterized by the XRD, a Philips XL-30 FEG scanning electron microscopy (SEM; Amsterdam, The Netherlands) and the TEM coupled with energy dispersive Xray (EDX) analysis. In order to evaluate mechanical properties under compression for comparison with the cited alloys, cylindrical specimens of $3 \mathrm{~mm}$ in diameter and $6 \mathrm{~mm}$ in length were tested in a universal testing machine (MTS testing system) under quasi-static loading at a strain rate of $5 \times 10^{-4} \mathrm{~s}^{-1}$. A small strain gauge was used to calibrate and measure the strain during loading. 


\section{Results}

Fig. 1a shows XRD patterns of the milled quinary alloy powders after various milling times. The XRD patterns exhibited all expected peaks of $\mathrm{Ti}, \mathrm{Nb}, \mathrm{Fe}, \mathrm{Co}$ and $\mathrm{Al}$ elements for the initial blended powder, showed a decreased intensity of diffraction peaks with increased milling time, and finally presented a single, high-angulardispersion diffraction maximum after $45 \mathrm{~h}$ milling, thereby indicating the formation of predominant glassy phase. Meanwhile, there exist minor $\beta$-Ti nanocrystals with grain sizes of about $5 \mathrm{~nm}$ remained in glassy matrix in the as-milled glassy powder, as seen in TEM image (not shown here). Because of its highly dense randompacked structure, long-range atomic rearrangement and grain growth can be effectively suppressed during sintering and crystallizing the as-milled glassy powder [27-29]. This is beneficial to the formation of ultrafine/nanostructured grains and concomitantly the fabrication of titanium alloys with higher strength accompanied by larger ductility [27,30,31]. Interestingly, with the added component number, the alloy system needs shorter critical milling time to maximizing the content of glassy phase in the asmilled ternary ( $55 \mathrm{~h})$, quaternary $(50 \mathrm{~h})$ and quinary ( $45 \mathrm{~h})$ glassy powders, as seen in the inset of Fig. 1a. This suggests the higher glass forming ability with the added component number. The viewpoint is reinforced by the higher thermal stability or the increased peak temperature of crystallization, the increased content of glassy phase or the increased heat release of crystallization $\left(\Delta H_{x}\right)$, respectively, from the as-milled ternary $\left(407^{\circ} \mathrm{C}\right.$ and $0.206 \mathrm{~kJ} /$ $\mathrm{mol})$, quaternary $\left(470^{\circ} \mathrm{C}\right.$ and $\left.1.173 \mathrm{~kJ} / \mathrm{mol}\right)$ and quinary $\left(520^{\circ} \mathrm{C}\right.$ and $2.215 \mathrm{~kJ} / \mathrm{mol}$ ) glassy powders (Fig. 1b), respectively. Reasonably, the higher glass forming ability agrees well the more dense randompacked structure in the as-milled glassy powders with the designed and added component number $[14,15]$.

As expected, it can be observed that two endothermic peaks represent the semi-solid temperature interval for the as-milled glassy powders (Fig. 1b). The first endothermic peaks, $1008{ }^{\circ} \mathrm{C}$ for the ternary, $1055^{\circ} \mathrm{C}$ for the quaternary, and $1100{ }^{\circ} \mathrm{C}$ for the quinary powder, indicate the formation of liquid phase stemmed from the eutectic reaction between bcc $\beta$-Ti and bcc Ti(Fe, Co). Note that fcc $\mathrm{Ti}_{2}(\mathrm{Co}, \mathrm{Fe})$ is a solid solution of Fe atoms substituting Co positions occupying node positions of the lattice in fcc $\mathrm{Ti}_{2} \mathrm{Co}$ compound. It has chemical characteristics of fcc $\mathrm{Ti}_{2} \mathrm{Fe}$. Because fcc $\mathrm{Ti}_{2} \mathrm{Fe}$ cannot react with bcc $\beta$-Ti in an eutectic pattern according to the Ti-Fe phase diagram [23], the substitution effect in $\mathrm{fcc}_{\mathrm{Ti}}(\mathrm{Co}, \mathrm{Fe})$ must somehow change the lattice to prevent a reaction with bcc $\beta$-Ti in a eutectic pattern. The substitution effect in $\mathrm{fcc} \mathrm{Ti}_{2}(\mathrm{Co}, \mathrm{Fe})$ increases the melting point of fcc $\mathrm{Ti}_{2} \mathrm{Co}$. Therefore, the second endothermic peaks in the DSC curves are simply attributed to the melting of remained solid phase, such as fcc $\mathrm{Ti}_{2}(\mathrm{Co}, \mathrm{Fe})$. Based on DSC analysis, we can determine the optimal SSS temperatures of $1010^{\circ} \mathrm{C}, 1050^{\circ} \mathrm{C}$ and $1100{ }^{\circ} \mathrm{C}$, respectively, for the as-milled ternary, quaternary and quinary glassy powders, respectively.

Fig. 2 shows XRD patterns of the SSSed and cast ternary, quaternary and quinary bulk alloys, respectively. For all cast alloys regardless of their component numbers, there are nearly same contents of the two phases, cubic cP2 bcc Pm $\overline{3} \mathrm{~m}(221) \mathrm{Ti}(\mathrm{Fe}, \mathrm{Co})$ and disordered cI2 bcc $\operatorname{Im} \overline{3} \mathrm{~m}(229) \beta$-Ti solid solutions (Table 2). It seems that the $\mathrm{Nb}$ and $\mathrm{Al}$ additions have no obvious effects on the phase constitution of the cast alloys. This may be associated with two reasons. The first is that the melting point in descending order is bcc $\beta$ - Ti, bcc $\mathrm{Ti}(\mathrm{Fe}, \mathrm{Co})$ and fcc $\mathrm{Ti}_{2}(\mathrm{Co}, \mathrm{Fe})$ thus causing the same sequence of phase solidification during cooling. The other is that the Fe and Co additions can also contribute to stabilizing bcc $\beta$-Ti in specific composition range according to Ti-Fe and Ti-Co binary phase diagrams [23]. As proved by chemical composition analysis of various crystalline phases in Table 1, the two reasons result into the depletion of Fe and Co elements for the formation of bcc $\beta$-Ti and bcc $\mathrm{Ti}(\mathrm{Fe}, \mathrm{Co})$ during cooling and concomitantly non-formation of fcc $\mathrm{Ti}_{2}(\mathrm{Co}, \mathrm{Fe})$ in the cast alloys (Fig. 2). In contrast, the SSSed alloys exhibit distinctly different phase constitutions with the cast counterparts (Table 2). First, all SSSed specimens have extra fcc $\mathrm{Ti}_{2}(\mathrm{Co}, \mathrm{Fe})$ together with bcc $\beta$-Ti and bcc Ti(Fe, Co). Second, the SSSed $\mathrm{Nb}$-containing quaternary specimen has the increased content of bcc $\beta$-Ti and simultaneous decreased content of fcc $\mathrm{Ti}_{2}(\mathrm{Co}$, Fe) compared with the SSSed Nb-free ternary one, and possesses the increased content of bcc $\beta$-Ti relative to the SSSed Al-containing quinary one (Fig. 2). In addition, it should be noted that all SSSed specimens have the left-shifted diffraction peaks of the bcc $\beta$-Ti compared to the cast counterparts. This is attributed to the smaller lattice constant of the bcc $\beta$-Ti induced by the smaller content of $\beta$ stabilizer. For example, the formation of extra fcc $\mathrm{Ti}_{2}(\mathrm{Co}, \mathrm{Fe})$ would consume partial Fe and Co $\beta$-stabilizers in the SSSed specimens.

Fig. 3 presents SEM microstructures of the SSSed and cast ternary, quaternary and quinary bulk alloys, respectively. The SSSed ternary sample exhibits ultrafine eutectic structure with

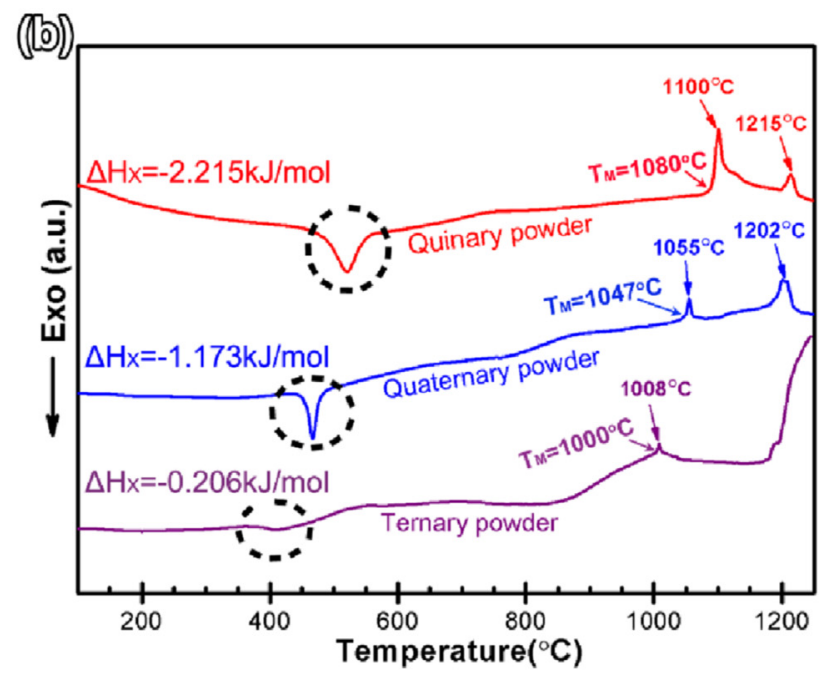

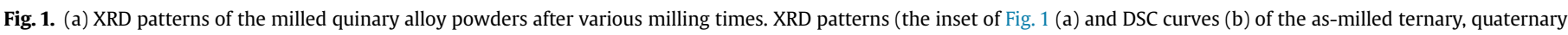
and quinary glassy powders after $55 \mathrm{~h}, 50 \mathrm{~h}$, and $45 \mathrm{~h}$ milling, respectively. 

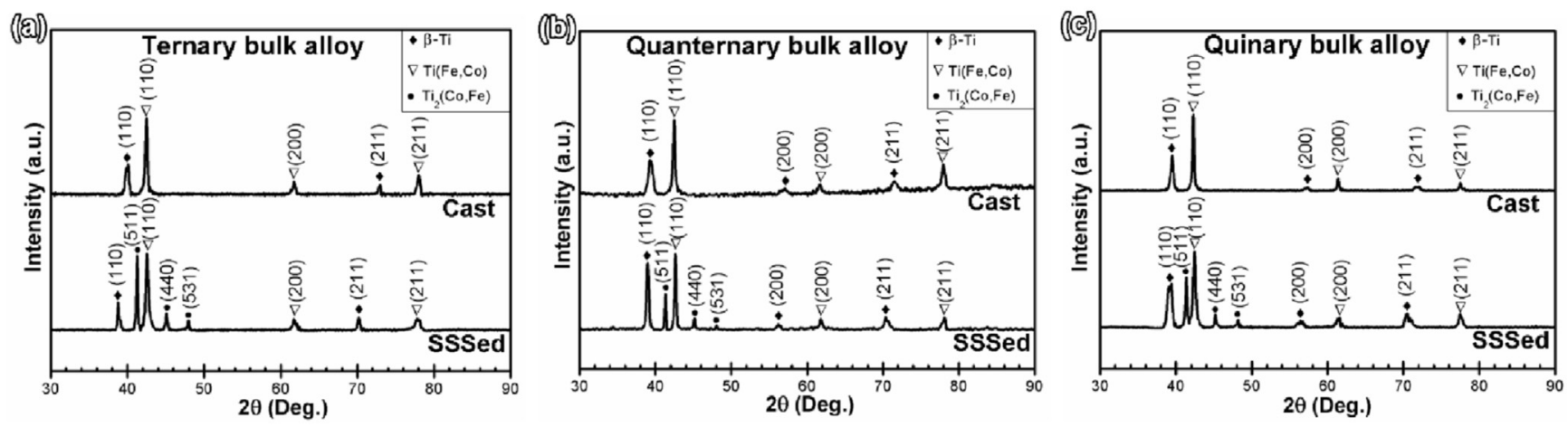

Fig. 2. XRD patterns of the SSSed and cast ternary (a), quaternary (b) and quinary (c) bulk alloys, respectively.

Table 1

Chemical composition of crystalline phases in the studied SSSed and cast bulk alloys.

\begin{tabular}{|c|c|c|c|}
\hline Alloy system & Process & Phases & Chemical composition \\
\hline \multirow[t]{5}{*}{$\left(\mathrm{Ti}_{70.56} \mathrm{Fe}_{29.44}\right)_{90} \mathrm{Co}_{10}$} & SSS & $\beta-\mathrm{Ti}$ & $\mathrm{Ti}_{88.35} \mathrm{Fe}_{9.73} \mathrm{Co}_{1.92}$ \\
\hline & & $\mathrm{Ti}(\mathrm{Fe}, \mathrm{Co})$ & $\mathrm{Ti}_{50.52} \mathrm{Fe}_{34.71} \mathrm{Co}_{14.77}$ \\
\hline & & $\mathrm{Ti}_{2}(\mathrm{Co}, \mathrm{Fe})$ & $\mathrm{Ti}_{66.06} \mathrm{Fe}_{21.82} \mathrm{Co}_{12.12}$ \\
\hline & Casting & $\beta-\mathrm{Ti}$ & $\mathrm{Ti}_{79.41} \mathrm{Fe}_{15.43} \mathrm{Co}_{5.16}$ \\
\hline & & $\mathrm{Ti}(\mathrm{Fe}, \mathrm{Co})$ & $\mathrm{Ti}_{53.2} \mathrm{Fe}_{33.11} \mathrm{Co}_{13.69}$ \\
\hline \multirow{5}{*}{$\left(\mathrm{Ti}_{63.5} \mathrm{Fe}_{26.5} \mathrm{Co}_{10}\right)_{87.8} \mathrm{Nb}_{12.2}$} & SSS & $\beta-\mathrm{Ti}$ & $\mathrm{Ti}_{57.22} \mathrm{Nb}_{34.93} \mathrm{Fe}_{7.29} \mathrm{Co}_{0.56}$ \\
\hline & & $\mathrm{Ti}(\mathrm{Fe}, \mathrm{Co})$ & $\mathrm{Ti}_{47.6} \mathrm{Nb}_{3.84} \mathrm{Fe}_{33.88} \mathrm{Co}_{14.68}$ \\
\hline & & $\mathrm{Ti}_{2}(\mathrm{Co}, \mathrm{Fe})$ & $\mathrm{Ti}_{59.87} \mathrm{Nb}_{8.26} \mathrm{Fe}_{20.32} \mathrm{Co}_{11.55}$ \\
\hline & Casting & $\beta-\mathrm{Ti}$ & $\mathrm{Ti}_{65.67} \mathrm{Nb}_{18.47} \mathrm{Fe}_{12.28} \mathrm{Co}_{3.58}$ \\
\hline & & $\mathrm{Ti}(\mathrm{Fe}, \mathrm{Co})$ & $\mathrm{Ti}_{50.03} \mathrm{Nb}_{2.73} \mathrm{Fe}_{31.51} \mathrm{Co}_{15.73}$ \\
\hline \multirow[t]{5}{*}{$\left(\mathrm{Ti}_{63.5} \mathrm{Fe}_{26.5} \mathrm{Co}_{10}\right)_{82} \mathrm{Nb}_{12.2} \mathrm{Al}_{5.8}$} & SSS & $\beta-\mathrm{Ti}$ & $\mathrm{Ti}_{50.44} \mathrm{Nb}_{35.21} \mathrm{Fe}_{3.73} \mathrm{Co}_{0.64} \mathrm{Al}_{9.98}$ \\
\hline & & $\mathrm{Ti}(\mathrm{Fe}, \mathrm{Co})$ & $\mathrm{Ti}_{45.65} \mathrm{Nb}_{4.7} \mathrm{Fe}_{31.63} \mathrm{Co}_{13.79} \mathrm{Al}_{4.23}$ \\
\hline & & $\mathrm{Ti}_{2}(\mathrm{Co}, \mathrm{Fe})$ & $\mathrm{Ti}_{59.24} \mathrm{Nb}_{5.32} \mathrm{Fe}_{22.32} \mathrm{Co}_{10.82} \mathrm{Al}_{2.3}$ \\
\hline & Casting & $\beta-\mathrm{Ti}$ & $\mathrm{Ti}_{60.31} \mathrm{Nb}_{20.07} \mathrm{Fe}_{9.32} \mathrm{Co}_{2.82} \mathrm{Al}_{7.48}$ \\
\hline & & $\mathrm{Ti}(\mathrm{Fe}, \mathrm{Co})$ & $\mathrm{Ti}_{46.21} \mathrm{Nb}_{3.8} \mathrm{Fe}_{32.14} \mathrm{Co}_{14.53} \mathrm{Al}_{3.32}$ \\
\hline
\end{tabular}
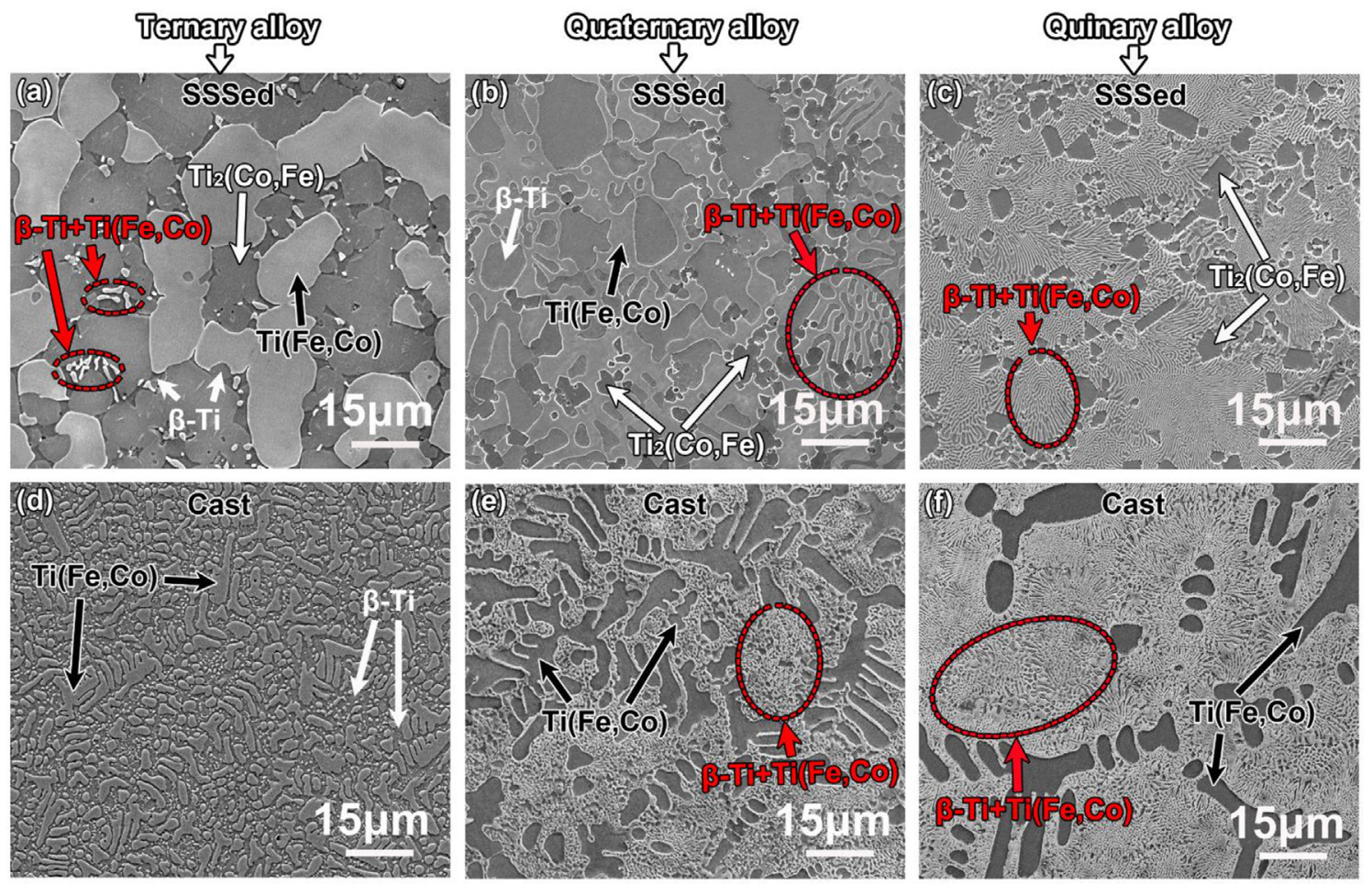

Fig. 3. SEM microstructures of the SSSed $(a-c)$ and cast $(d-f)$ ternary (a and d), quaternary (b and e) and quinary (c and f) bulk alloys, respectively. 
alternating bcc $\beta$-Ti and bcc Ti(Fe, Co) lamellae (marked by red dotted ellipses in Fig. 3a) together with coarse fcc $\mathrm{Ti}_{2}(\mathrm{Co}, \mathrm{Fe})$ and bcc $\mathrm{Ti}(\mathrm{Fe}, \mathrm{Co})$. Meanwhile, the eutectic lamellae have limited length and minor quantity. This agrees with relative small content of bcc $\beta$ $\mathrm{Ti}$ in Fig. 2a. With the increased component number, the SSSed Nbcontaining quaternary sample has partial fine lamellar eutectic matrix (marked by red dotted ellipses in Fig. 3b) accompanied by fine fcc $\mathrm{Ti}_{2}(\mathrm{Co}, \mathrm{Fe})$ and coarse bcc $\beta$-Ti. With the further increased component number, interestingly, the SSSed Al-containing quinary sample possesses a bimodal microstructure (Fig. 3c), a typical complete ultrafine lamellar eutectic matrix with alternating bcc $\beta$ $\mathrm{Ti}$ and bcc $\mathrm{Ti}(\mathrm{Fe}, \mathrm{Co})$ lamellae and fine equiaxed fcc $\mathrm{Ti}_{2}(\mathrm{Co}, \mathrm{Fe})$. The chemical composition of bcc $\beta$-Ti, bcc Ti(Fe, Co), and fcc $\mathrm{Ti}_{2}(\mathrm{Co}, \mathrm{Fe})$ phases in the SSSed bulk alloys are listed in Table 1, which was detected by EDX analysis in SEM and subsequent TEM. Obviously, phase morphologies and their distributions of the cast alloys are entirely different from the SSSed counterparts. First, all cast samples have typical lamellar eutectic structure with alternating bcc $\beta$ $\mathrm{Ti}$ and bcc Ti(Fe, Co) lamellae (Fig. 3d-f). Second, the cast Nbcontaining quaternary and quinary samples exhibit a microstructure of the lamellar eutectic matrix and coarse bcc Ti(Fe, Co) dispersed phase, compared with pure lamellar eutectic structure in the cast Nb-free ternary sample. The similar microstructural feature with the SSSed specimens is that the cast samples have finer eutectic lamellae with the increased component number. In addition, considering the contribution of the $\mathrm{Fe}$ and $\mathrm{Co}$ additions to stabilizing bcc $\beta$-Ti as discussed above, the chemical composition of bcc $\beta$-Ti and bcc $\mathrm{Ti}(\mathrm{Fe}, \mathrm{Co})$ in the cast samples is obviously higher than those in the SSSed counterparts (Table 1).

Fig. 4 shows TEM images, corresponding selected area electron diffraction (SAED) patterns and Fourier transformed patterns of the SSSed and cast ternary, quaternary and quinary bulk alloys, respectively. The SSSed ternary specimen has minor ultrafine bcc $\beta$ $\mathrm{Ti}$ and together with coarse fcc $\mathrm{Ti}_{2}(\mathrm{Co}, \mathrm{Fe})$ and bcc Ti(Fe, Co) (Figs. 3 and $4 a)$. Corresponding SAED patterns of the three constituted phases are indexed as the diffraction patterns of the bcc $\beta$-Ti (the inset), bcc $\mathrm{Ti}(\mathrm{Fe}, \mathrm{Co})$ (the inset), and $\mathrm{fcc} \mathrm{Ti}_{2}(\mathrm{Co}, \mathrm{Fe})$ (the inset), respectively, along the [001], [111], and [011] zone axis, respectively. In addition, bcc $\beta$-Ti and bcc $\mathrm{Ti}(\mathrm{Fe}, \mathrm{Co})$ do not share the same zone axis because of difficulty in observing minor lamellar eutectic in TEM analysis. With the increased component number, the partial fine lamellar eutectic structure with a lamellae width of $450-600 \mathrm{~nm}$ is accompanied by fine equiaxed fcc $\mathrm{Ti}_{2}(\mathrm{Co}, \mathrm{Fe})$ and coarse bcc $\beta$-Ti with respective grain sizes of $2 \mu \mathrm{m}-10 \mu \mathrm{m}$ and $5 \mu \mathrm{m}$ $20 \mu \mathrm{m}$ in the SSSed Nb-containing quaternary bimodal sample (Figs. 3 and $4 \mathrm{~b}$ ). Corresponding SAED patterns of the fine lamellar eutectic are indexed as the diffraction patterns of the bcc $\beta$-Ti and bcc Ti(Fe, $\mathrm{Co}$ ) all along the [1 11] zone axis (the insets), and the fcc $\mathrm{Ti}_{2}(\mathrm{Co}, \mathrm{Fe})$ is indexed as along the [011] zone axis (the inset). With the further increased component number, the typical ultrafine lamellar eutectic matrix has an average lamellae width of about $150-200 \mathrm{~nm}$, and the surrounded fine equiaxed fcc $\mathrm{Ti}_{2}(\mathrm{Co}, \mathrm{Fe})$ has a grain size of $5 \mu \mathrm{m}$ in the SSSed Al-containing quinary bimodal sample (Figs. 3 and 4c). To our best knowledge, this is the first to report this bimodal microstructure containing an ultrafine lamellar eutectic. Corresponding SAED patterns of the ultrafine lamellar eutectic matrix are indexed as the diffraction patterns of the bcc $\beta$ $\mathrm{Ti}$ and bcc Ti(Fe, Co) along the [001] zone axis (the inset), and the fcc $\mathrm{Ti}_{2}(\mathrm{Co}, \mathrm{Fe})$ is indexed as along the [011] zone axis (the inset). Further Fourier transformed patterns indicates that the eutectic phase boundaries between bcc $\beta$-Ti and bcc Ti(Fe, $\mathrm{Co}$ ) lamellae have a nearly completely coherent interface (Fig. 4e), which is a very steady state and is quite stable and difficult to destroy under load. Their corresponding orientation relationships are (110) $\beta$-Ti//(110) $\mathrm{Ti}(\mathrm{Fe}, \mathrm{Co})$. According to the ruler and the diffraction vectors in reciprocal space (Fig. 4c), the lattice parameters are $a_{\mathrm{bcc}} \beta$ $\mathrm{Ti}=0.3218 \mathrm{~nm}, a_{\mathrm{bcc}} \mathrm{Ti}(\mathrm{Fe}, \mathrm{Co})=0.3028 \mathrm{~nm}$, and $a_{\mathrm{fcc}} \mathrm{Ti} 2(\mathrm{Fe}$, Co) $=1.2972 \mathrm{~nm}$ in the SSSed quinary bimodal alloy, respectively. As for the cast quinary counterparts, the lamellae widths of the bcc $\beta$ $\mathrm{Ti}$ and bcc Ti(Fe, Co) is about $150-200 \mathrm{~nm}$ (Fig. 4d), which is about equivalent to those in the SSSed quinary bimodal sample. However, corresponding SAED and Fourier transformed patterns (Fig. 4d and f) of the lamellar eutectic phase boundaries, the bcc $\beta$-Ti (the inset) and bcc $\mathrm{Ti}(\mathrm{Fe}, \mathrm{Co})$ (the inset) all along the [001] zone axis, suggest a nearly semi-coherent interface (Fig. 4f), which is more destructible than that of a completely coherent interface in the SSSed quinary bimodal sample (Fig. 4c and e).

Fig. 5 displays compressive engineering stress-strain curves of the SSSed and cast ternary, quaternary and quinary bulk alloys, respectively. Evidently, all SSSed specimens have far superior strength and plasticity to those of the cast counterparts. For example, the fracture strength and the plasticity of the SSSed ternary specimen are about $350 \mathrm{MPa}$ and 3\% higher than those of the cast counterpart, respectively. Most interestingly, with the increased component number, the SSSed specimens exhibit significantly the increased strength and plasticity (Table 2 and Fig. 5), in accordance with the higher content and the finer lamellae of the eutectic structure in the SSSed bulk alloys (Fig. 3a-c). Noticeably, an outstanding yield plateau is followed by excellent work hardening behavior for the SSSed quaternary and quinary bimodal specimens. This leads to their excellent mechanical properties. For example, the SSSed quinary bimodal specimen has ultrahigh yield strength of $2050 \mathrm{MPa}$ and high fracture strength of $2897 \mathrm{MPa}$ as well as a large plasticity of $19.7 \%$ (subtraction between fracture strain (23\%) and yield strain (3.3\%). Its balanced strength and ductility is far superior to those of representative bimodal titanium alloys fabricated by rapid solidification reported so far (Table 2) [6,7,13,16,19-21,32-34]. Generally, yield strength is more important than fracture strength for practical engineering applications [21]. Therefore, the ultrahigh yield strength and large plasticity obtained here provides a possibility as structural material candidate for the SSSed alloys.

Fig. 6 shows fracture and surface morphologies of the SSSed ternary, quaternary and quinary bulk alloys, respectively. It is found that intergranular fracture together with minor ductile dimple is main feature of the SSSed ternary sample (Fig. 6a), consistent with its inferior mechanical property (Fig. 5 and Table 2), relative small content of the ductile bcc $\beta$-Ti (Fig. 2a), and the minor lamellar eutectic structure (Fig. 3a). With the increased component number, the SSSed quaternary bimodal sample has obvious fracture feature of increased content of ductile dimples, the coarse dimple (Fig. 6b) induced by ductile coarse bcc $\beta$-Ti (Fig. 3b) and the fine dimple marked by red dashed box originating from partial fine lamellar eutectic structure (Fig. 3b), agreeing with its moderate mechanical property (Fig. 5 and Table 2). With the further increased component number, there are many honeycomb-like dimples (marked as black arrows in Fig. 6c) induced by the shedding of fcc $\mathrm{Ti}_{2}(\mathrm{Co}, \mathrm{Fe})$ second strengthening particles in the SSSed quinary sample. Note that abundant ductile rod-like crimped tearing edges (marked as red arrows) result from the whole fracture of the ultrafine bcc $\beta$-Ti and bcc Ti(Fe, Co) lamellae (Fig. 6c), indicating excellent ability of plastic deformation. These are consistent with the microstructure of a typical ultrafine lamellar eutectic matrix and fine equiaxed fcc $\mathrm{Ti}_{2}(\mathrm{Co}, \mathrm{Fe})$ dispersed phase (Figs. 3 and 4c). Especially, the coherent interface between bcc $\beta$-Ti and bcc Ti(Fe, $\mathrm{Co}$ ) lamellae (Fig. 4c and e) contributes to the excellent mechanical properties of the SSSed quinary sample (Fig. 5 and Table 2). Additional SEM results obtained from the surface morphologies of the 15\%-strained SSSed quinary alloy indicate that only stretching, elongation and bending phenomena are observed for the ultrafine lamellar eutectic 

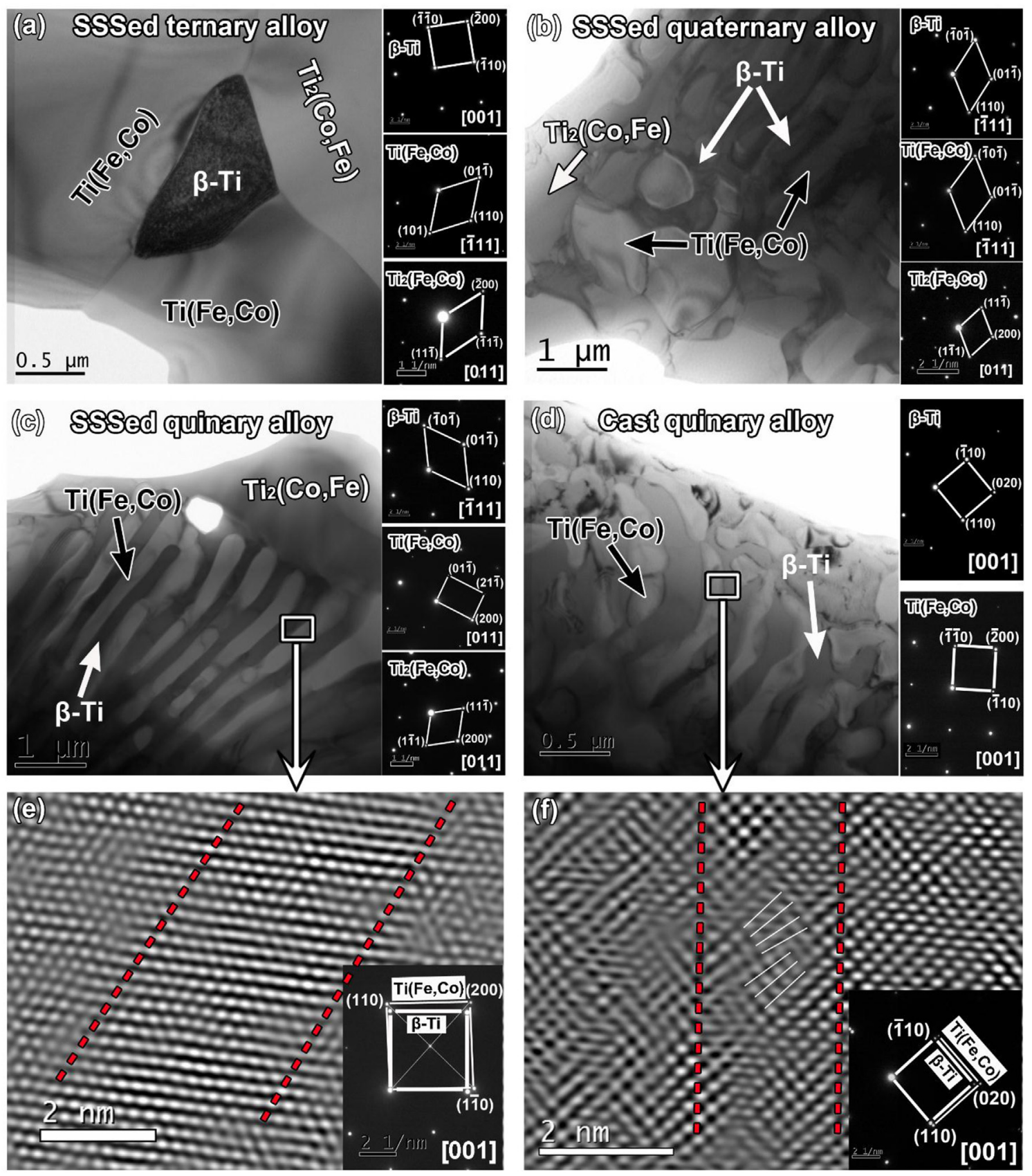

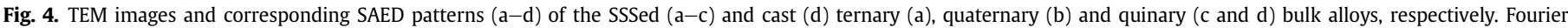
transformed patterns of the eutectic phase boundaries between bcc $\beta$-Ti and bcc Ti(Fe, Co) lamellae in the SSSed (e) and cast (f) quinary bulk alloys.

structure, as marked by the black arrows in Fig. 6d. Meanwhile, the coarse $\mathrm{Ti}_{2}(\mathrm{Co}, \mathrm{Fe})$ grains are fragmented from the ultrafine lamellar eutectic structure (Fig. 6e). Also, these surface morphologies agree well with the fracture morphologies of the SSSed quinary alloy. In contrast, the intergranular fracture of coarse bcc Ti(Fe, Co) (Figs. 3 and $6 \mathrm{f}$ ) and non-formation of rod-like crimped tearing edges result into the relative inferior mechanical property of the cast quinary counterpart.

\section{Discussion}

To clarify the formation mechanism of the lamellar eutectic structure in our study, sintering curve (lower part) and corresponding densification curve (upper part) of the as-milled quinary glassy powder is shown in Fig. 7. As an example, the insets describe microstructure evolution of resultant bimodal titanium alloys during SSS. Briefly, sintering process of the as-milled glassy powder, that is to say, corresponding microstructure evolution of resultant bimodal titanium alloys can be divided into five stages, i.e., rearrangement of powder particles (stage I), densification or crystallization of glassy powder (stage II), grain growth of crystallized phases (stage III), formation of liquid phase or semi-solid state (stage IV), and formation of bimodal microstructure (stage V). Each stage is distinguished exactly by the sudden increase of densification rate. In stage I below $380{ }^{\circ} \mathrm{C}$, the punch has no apparent displacement, implying that main densification mechanism of the powder is rearrangement of powder particles. In stage II ranging from $380{ }^{\circ} \mathrm{C}$ to $760{ }^{\circ} \mathrm{C}$, the punch displaces rapidly; the sintered 


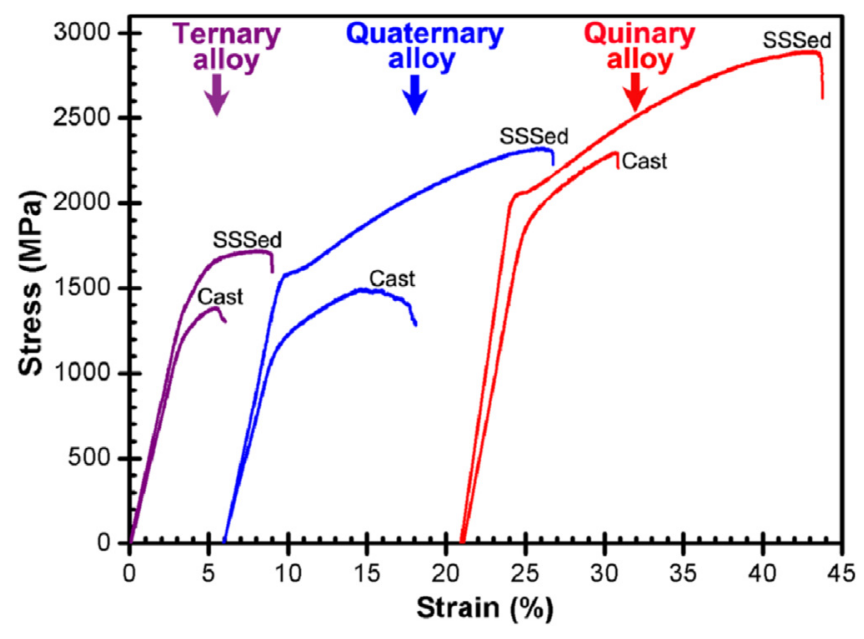

Fig. 5. Compressive engineering stress-strain curves of the SSSed and cast ternary, quaternary and quinary bulk alloys, respectively.

glassy powder begins to crystallize into $\beta$ - $\mathrm{Ti}, \mathrm{Ti}(\mathrm{Fe}, \mathrm{Co})$, and $\mathrm{Ti}_{2}(\mathrm{Co}$, $\mathrm{Fe}$ ) nano-grains, corresponding a rapid two-stage densification process resulted from the viscous flow of the glassy powder [31,35]. After densification process ends at $760{ }^{\circ} \mathrm{C}$, the sintered and crystallized sample enters stage III with continuous grain growth of the precipitated phases until forming ultrafine equiaxed grains $[22,27,28,30]$ at $1045^{\circ} \mathrm{C}$, accompanying no obvious change in punch displacement. Afterward, in stage IV with a significant feature forming semi-solid state, bcc $\beta$-Ti and bcc Ti(Fe, Co) phases react preferentially in an eutectic pattern to transform into liquid phase at $1050{ }^{\circ} \mathrm{C}$, demonstrated by an sudden increase of densification rate at temperature close to $1050{ }^{\circ} \mathrm{C}$ (marked as a red circle), while fcc $\mathrm{Ti}_{2}(\mathrm{Co}, \mathrm{Fe})$ still remains in the solid state and grows to micronsized equiaxed grains. Note that the temperature corresponding to the formation of a liquid phase recorded in SPS system, $1050{ }^{\circ} \mathrm{C}$, deviates from the onset melting temperature $\left(1080^{\circ} \mathrm{C}\right.$, Fig. $\left.1 \mathrm{~b}\right)$. This may be attributed to temperature variations caused by the $2 \mathrm{~mm}$ distance between the thermocouple and the edge of powders during the SSS experiments. At this exact moment, the sintering pressure was reduced from $30 \mathrm{MPa}$ to $20 \mathrm{MPa}$ to prevent extrusion of the resultant liquid phase. After that step, the semi-solid state was held at a constant temperature of $1100{ }^{\circ} \mathrm{C}$ under $20 \mathrm{MPa}$. Finally, in stage $\mathrm{V}$ the liquid phase is rapidly cooled and transforms in a eutectic pattern into ultrafine lamellar eutectic matrix with bcc $\beta$-Ti and bcc Ti(Fe, Co) (Figs. 3 and 4c), and any remaining micronsized fcc $\mathrm{Ti}_{2}(\mathrm{Co}, \mathrm{Fe})$ equiaxed grains are retained at room temperature (Figs. 3 and 4c).

The as-milled ternary and quaternary glassy powders experience the same five stages described above during SSS process. The obvious difference is that with the increased component number, the as-milled glassy powder has the increased $T_{S}$ and decreased $T_{E}$ (Table 3 ) induced by the higher thermal stability and the increased content of glassy phase (Fig. 1b), together with the increased $T_{M}$ and thus increased $\Delta T$ (Table 3 ) stemmed from the more dense randompacked structure of the eutectic reaction-induced liquid phase. Especially, the increased components tailor the content of the three constituted phases formed in stage II and III, bcc $\beta$-Ti, bcc Ti(Fe, Co) and fcc $\mathrm{Ti}_{2}(\mathrm{Co}, \mathrm{Fe})$, and thus regulate phase composition (Table 1 ) of eutectic reaction in stage IV as designed. As such, the different phase contents for the SSSed specimens (Fig. 2) are due to the following reasons. During SSS, the preferential eutectic transformation reaction between bcc $\beta$-Ti and bcc $\mathrm{Ti}(\mathrm{Fe}, \mathrm{Co})$, and fcc $\mathrm{Ti}_{2}(\mathrm{Co}, \mathrm{Fe})$ always keeps solid state. The $\mathrm{Nb}$ addition in the quaternary glassy powder promotes the formation of higher content bcc $\beta$-Ti compared with the Nb-free ternary one; the Al addition in the quinary one has opposite effect of stabilizing $\beta$-Ti relative to the Al-free quaternary one. Briefly stated, the reversible metallurgical process of solid-liquid phase transformation in stage IV gives rise to different phase contents in the SSSed specimens with different component numbers. Therefore, the different phase contents lead to that the morphology and distribution of the eutectic structure in stage $\mathrm{V}$ transforms from the limited length and minor quantity in the SSSed ternary sample (Figs. 3 and $4 \mathrm{a}$ ), to the partial fine alternating lamellae in the SSSed quaternary bimodal one (Figs. 3 and $4 \mathrm{~b}$ ), and further to the typical complete ultrafine alternating continuous lamellae in the SSSed quinary bimodal one (Figs. 3 and 4c). Perfectly, this transformation process reflects the aforementioned design idea of controlling the phase composition of eutectic reaction, and consequently regulating the structure of eutectic reaction-induced liquid phase in stage IV. That is to say, the more component number the alloy system (Table 1), the more dense random-packed structure the eutectic reaction-induced liquid phase in stage IV, the higher content the eutectic structure and the

Table 2

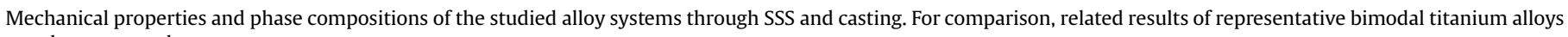
are also presented.

\begin{tabular}{|c|c|c|c|c|c|}
\hline Alloy system & Process & $\sigma_{y}(\mathrm{MPa})$ & $\sigma_{u}(\mathrm{MPa})$ & $\varepsilon_{p}(\%)$ & Main phases \\
\hline \multirow[t]{2}{*}{$\left(\mathrm{Ti}_{70.56} \mathrm{Fe}_{29.44}\right)_{90} \mathrm{Co}_{10}$ (Present work) } & SSS & $1400 \pm 6$ & $1721 \pm 10$ & $6 \pm 0.3$ & $\beta-\mathrm{Ti}, \mathrm{Ti}(\mathrm{Fe}, \mathrm{Co}), \mathrm{Ti}_{2}(\mathrm{Co}, \mathrm{Fe})$ \\
\hline & Casting & $1180 \pm 5$ & $1395 \pm 7$ & $3.2 \pm 0.2$ & $\beta-\mathrm{Ti}, \mathrm{Ti}(\mathrm{Fe}, \mathrm{Co})$ \\
\hline \multirow[t]{2}{*}{$\left(\mathrm{Ti}_{63.5} \mathrm{Fe}_{26.5} \mathrm{Co}_{10}\right)_{87.8} \mathrm{Nb}_{12.2}$ (Present work) } & SSS & $1551 \pm 8$ & $2329 \pm 8$ & $16.8 \pm 0.4$ & $\beta$-Ti, Ti(Fe, Co), $\mathrm{Ti}_{2}(\mathrm{Co}, \mathrm{Fe})$ \\
\hline & Casting & $1150 \pm 5$ & $1510 \pm 10$ & $9 \pm 0.2$ & $\beta-\mathrm{Ti}, \mathrm{Ti}(\mathrm{Fe}, \mathrm{Co})$ \\
\hline \multirow[t]{2}{*}{$\left(\mathrm{Ti}_{63.5} \mathrm{Fe}_{26.5} \mathrm{Co}_{10}\right)_{82} \mathrm{Nb}_{12.2} \mathrm{Al}_{5.8}$ (Present work) } & SSS & $2050 \pm 8$ & $2897 \pm 5$ & $19.7 \pm 0.5$ & $\beta$-Ti, Ti(Fe, Co), $\mathrm{Ti}_{2}(\mathrm{Co}, \mathrm{Fe})$ \\
\hline & Casting & $1750 \pm 3$ & $2300 \pm 3$ & $6.2 \pm 0.3$ & $\beta-\mathrm{Ti}, \mathrm{Ti}(\mathrm{Fe}, \mathrm{Co})$ \\
\hline$\left(\mathrm{Ti}_{0.72} \mathrm{Fe}_{0.28}\right)_{100-\mathrm{x}} \mathrm{Ta}_{\mathrm{x}}(0 \leq \mathrm{x} \leq 4)[6]$ & Casting & $>2000$ & $>2500$ & $5-7.5$ & $\beta$-Ti, TiFe \\
\hline $\mathrm{Ti}-\mathrm{Fe}-\mathrm{Co}[7]$ & Casting & $905-1860$ & $905-2350$ & $0.1-16.5$ & $\beta-\mathrm{Ti}, \mathrm{TiFe} / \mathrm{Ti}(\mathrm{Fe}, \mathrm{Co}), \mathrm{Ti}_{2} \mathrm{Co}, \alpha-\mathrm{Ti}$ \\
\hline $\mathrm{Ti}_{66} \mathrm{Nb}_{13} \mathrm{Cu}_{8} \mathrm{Ni}_{6.8} \mathrm{Al}_{6.2}[13]$ & Casting & $1170-1195$ & $2031-2043$ & $23.4-29.2$ & $\beta-\mathrm{Ti},(\mathrm{Cu}, \mathrm{Ni}) \mathrm{Ti}_{2},(\mathrm{Cu}, \mathrm{Ni}) \mathrm{Ti}$ \\
\hline$\left(\mathrm{Ti}_{0.705} \mathrm{Fe}_{0.295}\right)_{96.15} \mathrm{Sn}_{3.85}[16]$ & Casting & 1794 & 2260 & 7.5 & $\beta$-Ti, TiFe \\
\hline $\begin{array}{l}\left(\mathrm{Ti}_{70.5} \mathrm{Fe}_{29.5}\right)_{100-\mathrm{x}} \mathrm{V}_{\mathrm{x}}[19] \\
\mathrm{x}=0,1,3\end{array}$ & Casting & - & $2100-2200$ & $1.5-3.5$ & primary $\omega$-phase, $\beta$-Ti, TiFe \\
\hline $\mathrm{Ti}_{68} \mathrm{Fe}_{28.5} \operatorname{In}_{3.5}[20]$ & Casting & $1893 \pm 15$ & $2168 \pm 40$ & $1.61 \pm 0.4$ & $\beta-\mathrm{Ti}, \mathrm{Ti}(\mathrm{Fe}, \mathrm{In})$ \\
\hline $\mathrm{Ti}_{66} \mathrm{Fe}_{27.5} \operatorname{In}_{3.5} \mathrm{Nb}_{3}[20]$ & Casting & $2175 \pm 12$ & $2498 \pm 55$ & $3.6 \pm 0.6$ & $\beta-\mathrm{Ti}, \mathrm{Ti}(\mathrm{Fe}, \mathrm{In}, \mathrm{Nb})$ \\
\hline$\left(\mathrm{Ti}_{0.705} \mathrm{Fe}_{0.295}\right)_{100-\mathrm{x}} \mathrm{Ga}_{\mathrm{x}}(0 \leq \mathrm{x} \leq 2)[21]$ & Casting & $1882-2470$ & $1926-2930$ & $0.43-5.08$ & $\beta$-Ti, Ti(Fe, Ga) \\
\hline$\left(\mathrm{Ti}_{65} \mathrm{Fe}_{35}\right)_{93.15} \mathrm{Sn}_{3.85} \mathrm{Nb}_{3}[32]$ & Casting & 1250 & 2700 & 15 & $\beta$-Ti, TiFe \\
\hline $\mathrm{Ti}_{60} \mathrm{Cu}_{14} \mathrm{Ni}_{12} \mathrm{Sn}_{4} \mathrm{M}_{10}[33]$ (M: Mo, Nb and Ta) & Casting & $1037-1755$ & $2196-2578$ & $1.68-21.34$ & $\beta-\mathrm{Ti}, \alpha-\mathrm{Ti}$ \\
\hline $\mathrm{Ti}_{50.5} \mathrm{Fe}_{49.5}[34]$ & Casting & $1638.75-2102.36$ & $2192.37-2487.79$ & $7.26-16.6$ & $\beta$-Ti, TiFe \\
\hline
\end{tabular}

$\sigma_{\mathrm{y}}$ is yield strength; $\sigma_{u}$ is ultimate strength; $\varepsilon_{p}$ is plastic strain in percents. 

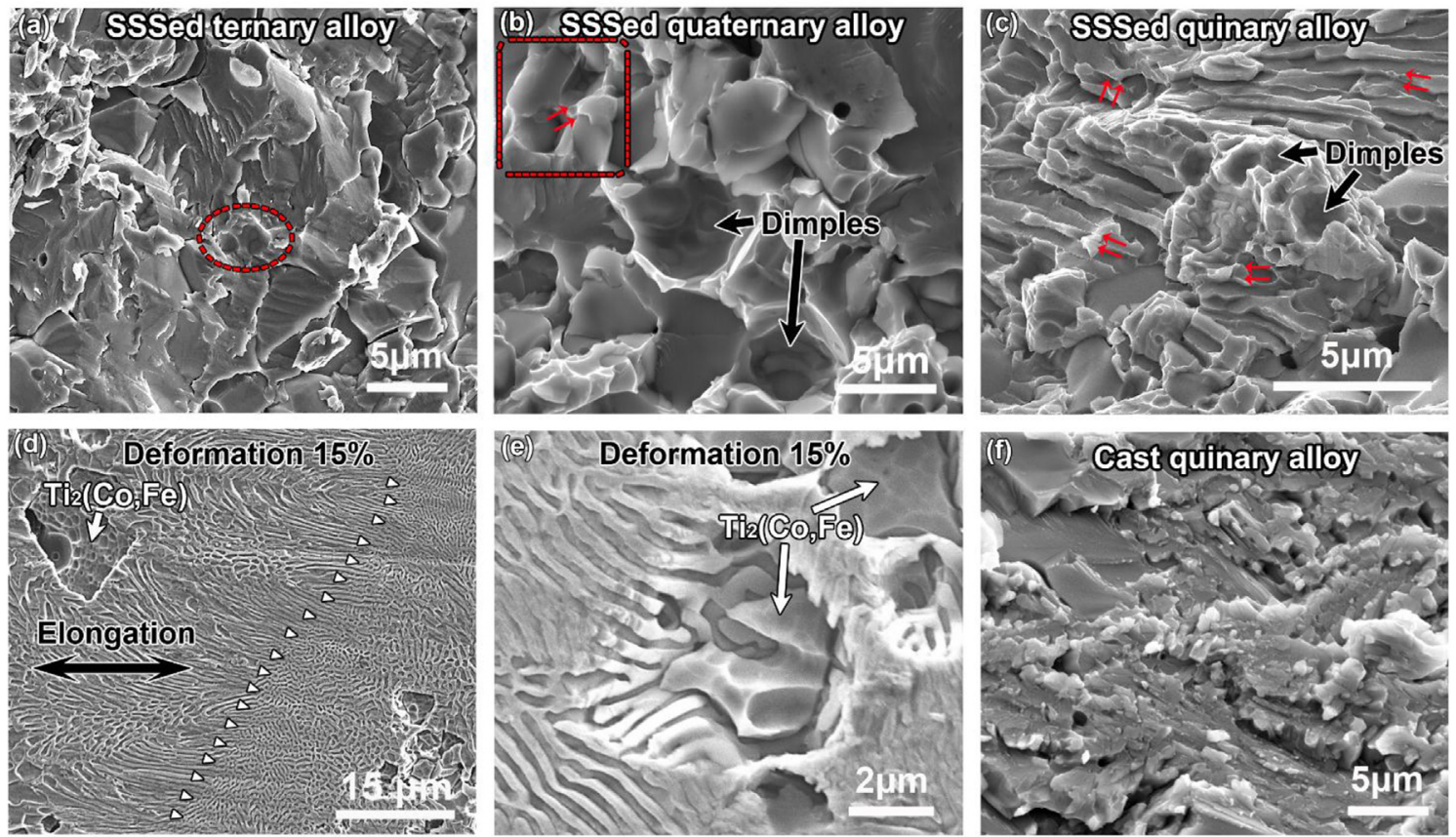

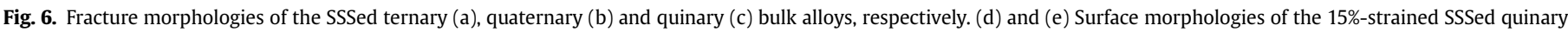
bulk alloy. (f) Fracture morphology of the cast quinary bulk alloy.

finer eutectic lamellae the SSSed bulk alloy in stage V. In summary, the same mechanisms governing the formation of a liquid phase in stage IV proves that SSS is required in order to attain a bimodal microstructure.

\section{Conclusions}

An innovative strategy involving controlling the phase composition and thus regulating the structure of liquid phase during a eutectic reaction induced by adjusting component number was

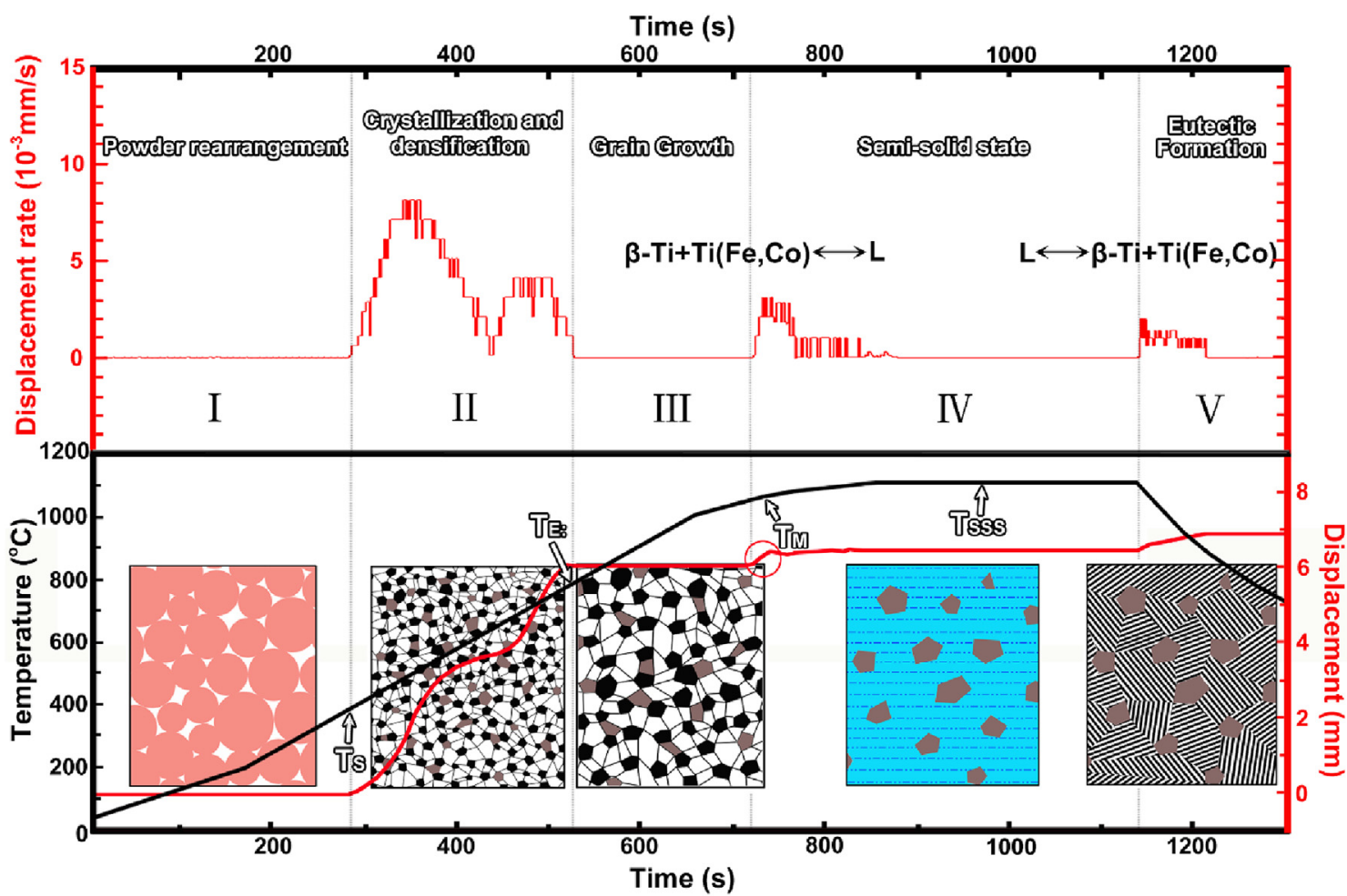

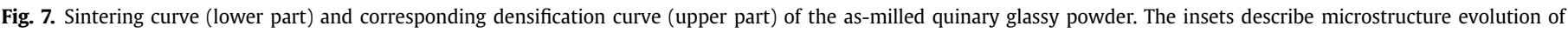
resultant bimodal titanium alloys during SSS. 
Table 3

Characteristic temperatures of the as-milled ternary, quaternary and quinary glassy powders during SSS. Note all temperatures are determined by the sudden increase of densification rate for respective glassy powders. $T_{S}$ start temperature of densification; $T_{E}$ end temperature of densification; $T_{M}$ melting temperature forming eutectic liquid phase, $\Delta T$ temperature interval between $\mathrm{T}_{\mathrm{M}}$ and $\mathrm{T}_{\mathrm{E}}, T_{S S S}$ selected SSS temperature.

\begin{tabular}{llllll}
\hline Alloy systems & $T_{S}\left({ }^{\circ} \mathrm{C}\right)$ & $T_{E}\left({ }^{\circ} \mathrm{C}\right)$ & $T_{M}\left({ }^{\circ} \mathrm{C}\right)$ & $\Delta T\left(\mathrm{~T}_{\mathrm{M}}-\mathrm{T}_{\mathrm{E}}\right)$ & $T_{S S S}\left({ }^{\circ} \mathrm{C}\right)$ \\
\hline$\left(\mathrm{Ti}_{70.56} \mathrm{Fe}_{29.44}\right)_{90} \mathrm{Co}_{10}$ & 324 & 921 & 994 & 73 & 1010 \\
$\left(\mathrm{Ti}_{63.5} \mathrm{Fe}_{26.5} \mathrm{Co}_{10}\right)_{87.8} \mathrm{Nb}_{12.2}$ & 358 & 860 & 1020 & 160 & 1050 \\
$\left(\mathrm{Ti}_{63.5} \mathrm{Fe}_{26.5} \mathrm{Co}_{10}\right)_{82} \mathrm{Nb}_{12.2} \mathrm{Al}_{5.8}$ & 380 & 760 & 1050 & 290 & 1100 \\
\hline
\end{tabular}

described to fabricate bimodal alloys by solid-solid sintering of mechanically alloyed glassy powder. With the addition of $\mathrm{Nb}$ and further $\mathrm{Al}$, the resultant quaternary and quinary bimodal alloys have higher content and finer size of lamellar eutectic structure with alternating bcc $\beta$-Ti and $\mathrm{Ti}(\mathrm{Fe}, \mathrm{Co})$ lamellae compared with ternary TiFeCo alloy. This is attributed to the more dense randompacked structure of the eutectic reaction-induced liquid phase. Especially, typical ultrafine lamellar eutectic matrix is accompanied by a coarse equiaxed fcc $\mathrm{Ti}_{2}(\mathrm{Co}, \mathrm{Fe})$ in the resultant quinary bimodal alloy. Its balanced strength and ductility is far superior to those of representative bimodal titanium alloys fabricated by rapid solidification reported so far. Our findings will help promoting endeavors to obtain excellent mechanical property for metallic materials with high melting point.

\section{Acknowledgments}

This work was supported by the National Natural Science Foundation of China (Nos. 51574128 and 11372323), the Guangdong Natural Science Foundation for Research Team (No. 2015A030312003), the Guangdong Application-oriented Special Funds for Science and Technology R\&D (No. 2016B090931002), and the Guangdong Special Funds for Public Welfare Research and Capacity Building (No. 2014A010105020).

\section{References}

[1] G. He, J. Eckert, W. Loser, L. Schultz, Novel Ti-base nanostructure-dendrite composite with enhanced plasticity, Nat. Mater. 2 (2003) 33-37.

[2] G. He, J. Eckert, W. Löser, M. Hagiwara, Composition dependence of the microstructure and the mechanical properties of nano/ultrafine-structured Ti-Cu-Ni-Sn-Nb alloys, Acta Mater. 52 (2004) 3035-3046.

[3] J.H. Han, K.B. Kim, S. Yi, J.M. Park, S.W. Sohn, T.E. Kim, D.H. Kim, J. Das, J. Eckert, Formation of a bimodal eutectic structure in Ti-Fe-Sn alloys with enhanced plasticity, Appl. Phys. Lett. 93 (2008) 141901.

[4] J. Das, F. Ettingshausen, J. Eckert, Ti-base nanoeutectic-hexagonal structured (D019) dendrite composite, Scr. Mater. 58 (2008) 631-634.

[5] I.V. Okulov, U. Kühn, T. Marr, J. Freudenberger, L. Schultz, C.G. Oertel W. Skrotzki, J. Eckert, Deformation and fracture behavior of composite structured Ti-Nb-Al-Co(-Ni) alloys, Appl. Phys. Lett. 104 (2014) 071905.

[6] L.C. Zhang, H.B. Lu, C. Mickel, J. Eckert, Ductile ultrafine-grained Ti-based alloys with high yield strength, Appl. Phys. Lett. 91 (2007) 051906.

[7] D.V. Louzguine-Luzgin, L.V. Louzguina-Luzgina, H. Kato, A. Inoue, Investigation of Ti-Fe-Co bulk alloys with high strength and enhanced ductility, Acta Mater. 53 (2005) 2009-2017.

[8] L.C. Zhang, J. Das, H.B. Lu, C. Duhamel, M. Calin, J. Eckert, High strength Ti-Fe-Sn ultrafine composites with large plasticity, Scr. Mater. 57 (2007) $101-104$.

[9] D.K. Yang, P.D. Hodgson, C.E. Wen, Simultaneously enhanced strength and ductility of titanium via multimodal grain structure, Scr. Mater. 63 (2010) 941-944.

[10] W.H. Yin, F. Xu, O. Ertorer, Z. Pan, X.Y. Zhang, L.J. Kecskes, E.J. Lavernia, Q. Wei,
Mechanical behavior of microstructure engineered multi-length-scale titanium over a wide range of strain rates, Acta Mater. 61 (2013) 3781-3798.

[11] Y. Long, T. Wang, H.Y. Zhang, X.L. Huang, Enhanced ductility in a bimodal ultrafine-grained Ti-6Al-4V alloy fabricated by high energy ball milling and spark plasma sintering, Mater. Sci. Eng. A 608 (2014) 82-89.

[12] B. Srinivasarao, K. Oh-ishi, T. Ohkubo, K. Hono, Bimodally grained highstrength Fe fabricated by mechanical alloying and spark plasma sintering, Acta Mater. 57 (2009) 3277-3286.

[13] U. Kühn, N. Mattern, A. Gebert, M. Kusy, M. Boström, U. Siegel, L. Schultz, Nanostructured $\mathrm{Zr}$ - and Ti-based composite materials with high strength and enhanced plasticity, J. Appl. Phys. 98 (2005) 054307.

[14] A. Inoue, Stabilization of metallic supercooled liquid and bulk amorphous alloys, Acta Mater, 48 (2000) 279-306.

[15] A. Inoue, A. Takeuchi, Recent development and application products of bulk glassy alloys, Acta Mater. 59 (2011) 2243-2267.

[16] J. Das, K.B. Kim, F. Baier, W. Löser, J. Eckert, High-strength Ti-base ultrafine eutectic with enhanced ductility, Appl. Phys. Lett. 87 (2005) 161907.

[17] G.H. Cao, N. Liu, J.C. Peng, X. Li, G.J. Shen, A.M. Russell, Transmission electron microscopy study of the microstructure of a $\mathrm{Ti}-\mathrm{Fe}-\mathrm{Zr}$ alloy, Mater. Charact. 83 (2013) 43-48.

[18] G.H. Cao, Y.F. Peng, N. Liu, X. Li, Z.S. Lei, Z.M. Ren, D. Gerthsen, A.M. Russell, Formation of a bimodal structure in ultrafine $\mathrm{Ti}-\mathrm{Fe}-\mathrm{Nb}$ alloys with highstrength and enhanced ductility, Mater. Sci. Eng. A 609 (2014) 60-64.

[19] J.H. Han, G.A. Song, J.M. Park, J.K. Lee, S. Yi, D.H. Kim, K.B. Kim, Microstructural modulation of $\mathrm{Ti}-\mathrm{Fe}-\mathrm{V}$ ultrafine eutectic alloys with enhanced mechanical properties, J. Alloys Compd. 491 (2010) 178-181.

[20] D.K. Misra, S.W. Sohn, H. Gabrisch, W.T. Kim, D.H. Kim, High strength $\mathrm{Ti}-\mathrm{Fe}-(\mathrm{In}, \mathrm{Nb})$ composites with improved plasticity, Intermetallics 18 (2010) $342-347$.

[21] D.K. Misra, R.K. Rakshit, M. Singh, P.K. Shukla, K.M. Chaturvedi, B. Sivaiah, B. Gahtori, A. Dhar, S.W. Sohn, W.T. Kim, D.H. Kim, High yield strength bulk Ti based bimodal ultrafine eutectic composites with enhanced plasticity, Mater. Des. 58 (2014) 551-556.

[22] L.H. Liu, C. Yang L.M. Kang S.G. Ou, X.O Li, W.W. Zhang W.P. Chen, Y.Y. Li, P.J. Li, L.C. Zhang, A new insight into high-strength $\mathrm{Ti}_{62} \mathrm{Nb}_{12.2} \mathrm{Fe}_{13.6} \mathrm{Co}_{6.4} \mathrm{Al}_{5.8}$ alloys with bimodal microstructure fabricated by semi-solid sintering, Sci. Rep. 6 (2016) 23467.

[23] F.N. Rhines, Phase Diagrams in Metallurgy, McGraw-Hill, New York, 1956.

[24] R. Sahara, S. Emura, K. Tsuchiya, Theoretical investigation of effect of alloying elements on phase stability in body-centered cubic Ti-X alloys ( $\mathrm{X}=\mathrm{V}, \mathrm{Cr}, \mathrm{Fe}$, Co, Nb, and Mo), J. Alloys Compd. 634 (2015) 193-199.

[25] W. Hume-rothery, E. Anderson, Eutectic compositions and liquid immiscibility in certain binary alloys, Philos. Mag. 5 (1960) 383-405.

[26] D.V. Louzguine-Luzgin, L.V. Louzguina-Luzgina, V.I. Polkin, A. Inoue, Deformation-induced transformations in $\mathrm{Ti}_{60} \mathrm{Fe}_{20} \mathrm{Co}_{20}$ alloy, Scr. Mater. 57 (2007) 445-448.

[27] Y.Y. Li, C. Yang, S.G. Qu, X.Q. Li, W.P. Chen, Nucleation and growth mechanism of crystalline phase for fabrication of ultrafine-grained $\mathrm{Ti}_{66} \mathrm{Nb}_{13} \mathrm{Cu}_{8} \mathrm{Ni}_{6.8} \mathrm{Al}_{62}$ composites by spark plasma sintering and crystallization of amorphous phase, Mater. Sci. Eng. A 528 (2010) 486-493.

[28] L.H. Liu, C. Yang, L.M. Kang, Y. Long, Z.Y. Xiao, P.J. Li, L.C. Zhang, Equiaxed Tibased composites with high strength and large plasticity prepared by sintering and crystallizing amorphous powder, Mater. Sci. Eng. A 650 (2016) $171-182$.

[29] C. Suryanarayana, N. Al-Aqeeli, Mechanically alloyed nanocomposites, Prog. Mater. Sci. 58 (2013) 383-502.

[30] C. Yang, L.H. Liu, Q.R. Cheng, D.D. You, Y.Y. Li, Equiaxed grained structure: a structure in titanium alloys with higher compressive mechanical properties, Mater. Sci. Eng. A 580 (2013) 397-405.

[31] C. Yang, L.H. Liu, Y.G. Yao, Y.H. Li, Y.Y. Li, Intrinsic relationship between crystallization mechanism of metallic glass powder and microstructure of bulk alloys fabricated by powder consolidation and crystallization of amorphous phase, J. Alloys Compd. 586 (2014) 542-548.

[32] G.H. Cao, Y.N. Zhou, N. Liu, X. Li, A.M. Russell, D. Gerthsen, High-strength bimodal ultrafine Ti-based alloys with enhanced ductility, Cryst. Res. Technol. 49 (2014) 338-344.

[33] G. He, J. Eckert, Q.L. Dai, M.L. Sui, W. Löser, M. Hagiwara, E. Ma, Nanostructured Ti-based multi-component alloys with potential for biomedical applications, Biomaterials 24 (2003) 5115-5120.

[34] A. Schlieter, U. Kühn, J. Eckert, W. Löser, T. Gemming, M. Friák, J. Neugebauer, Anisotropic mechanical behavior of ultrafine eutectic TiFe cast under nonequilibrium conditions, Intermetallics 19 (2011) 327-335.

[35] L.H. Liu, C. Yang, Y.G. Yao, F. Wang, W.W. Zhang, Y. Long, Y.Y. Li, Densification mechanism of Ti-based metallic glass powders during spark plasma sintering process, Intermetallics 66 (2015) 1-7. 